\title{
ESPIRITUALIDADE CRISTÃ, POLÍTICAS PÚBLICAS E ENVELHECIMENTO: LIMITES E POSSIBILIDADES NO CENÁRIO CONTEMPORÂNEO
}

Christian spirituality, public policies and aging: limits and possibilities in the contemporary scenario

\author{
Flávio da Silva Chaves. ${ }^{1}$ \\ Crisóstomo Lima do Nascimento. ${ }^{2}$
}

\begin{abstract}
RESUMO
A presente pesquisa tem por objetivo apresentar a espiritualidade cristã como uma base de referência para a intervenção no campo da saúde do idoso, considerando os seus limites e possibilidades no contexto atual. Por esse viés, pretende-se aliar espiritualidade e políticas públicas num processo interdisciplinar que viabilize práticas complementares no processo do envelhecimento saudável. A partir da revisão bibliográfica qualitativa ponderou-se a fragilidade das políticas públicas do idoso num conflito entre teoria e prática das Leis de amparo ao idoso, a relação entre fé e política na transformação social e, por último, a intersecção entre a espiritualidade judaico cristã e as políticas públicas no cuidado do humano. Constata-se que, para uma ação eficaz no contemporâneo, frente as mais variadas demandas, seja necessário um afastamento das discussões políticas e religiosas de cunho ideológico, para um diálogo que leve em consideração a multidimensionalidade do humano em seus mais variados contextos.
\end{abstract}

Palavras-chave: Espiritualidade; Políticas Públicas; Envelhecimento.

\begin{abstract}
This research aims to present christian spirituality as a reference base for intervention in the field of elderly health, considering its limits and possibilities in the current context. Through this bias, it is intended to combine spirituality and public policies in an interdisciplinary process that enables complementary practices in the healthy aging process. From the qualitative bibliographic review, the fragility of public policies for the elderly was considered in a conflict between theory and practice of the Laws for the protection of the elderly, the relationship between faith and politics in social transformation and, finally, the intersection between JewishChristian spirituality and public policies in human care. It appears that, for an effective action in the contemporary, facing the most varied demands, it is necessary to move away from political and religious discussions of an ideological nature, towards a dialogue that takes into account the multidimensionality of the human in its most varied contexts.
\end{abstract}

Keywords: Spirituality; Public policy; Aging.

\footnotetext{
1 Mestre em Ciências das Religiões; Especialista em Psicoterapia Existencial e Gestal-Terapia (ISECENSA); Psicólogo Clínico; Professor da Faculdade Batista do Estado do Rio de Janeiro (FABERJ); Doutorando em Cognição e Linguagem (UENF).

${ }^{2}$ Psicólogo Clínico, Doutor em Educação pela Faculdade de Educação da Universidade Federal Fluminense; Mestre em estudos da subjetividade com ênfase em Fenomenologia pelo Programa de Pós-graduação em Psicologia da Universidade Federal Fluminense, com graduação, bacharelado e licenciatura em Psicologia pela mesma instituição, pós-graduação em Filosofia e Pós-doutorando em Ciências da religião pelo PPG da PUCCampinas.
}

REVISTA RELEGENS THRÉSKEIA - 2021 - UFPR 


\section{Introdução}

A presente pesquisa tem por objetivo apresentar a espiritualidade cristã como base de referência para a intervenção no campo da saúde do idoso, considerando os seus limites e possibilidades no contexto atual. Ainda que a exposição seja pelo viés da espiritualidade cristã, não se pretende negar ou fazer juízo de valor em detrimento a outros modos de vivenciar o sagrado ou apresentar esta como absoluta em relação as intervenções no campo das políticas públicas. Reitera-se, ainda, que a espiritualidade, nesse contexto, é entendida como um instrumento que confere sentido à existência (FRANKL, 2007; 2008) e pensada enquanto emoções positivas (VAILLANT, 2010), podendo ser um instrumento de (re) significação do sentido do self (JUNG, 1978), abrindo, dessa forma, o debate entre religião e esfera pública ${ }^{3}$ (BIRMAN, 2003; GOHN, 2011).

Sendo assim, a partir da Lei Constitucional Lei n. ${ }^{\circ} 10.741,1^{\circ}$ de outubro de 2003 e autores como Manhãs, Istoe e Souza (2015), Mendes et al (2015), Camarano e Pasina (2018) consideramos os aspectos positivos das Leis de amparo ao idoso em detrimento aos seus pontos negativos em sua prática intervencionista. Em seguida, articulando os conceitos entre fé e politica foi necessário a problematização desta relação (LIED \& HAMES (2010), pontuando os pontos divergentes de abordagem e, respectivamente, a sua autonomia nas intervenções sociais (JÚNIOR, 2009). Neste sentido, para a intersecção entre política e religião, o papel da segunda está ligado ao suspiro dos oprimidos (ALVES, 1984) e não nas discussões e estabelecimento de regras econômicas, função política.

Logo, respeitando cada qual o seu campo de abordagem, fé e política são fundamentais para o desenvolvimento humano (SILVA, 2008), atuando enquanto fonte de saúde, sentido e significado da vida (DE PAULA, 2012; AMATUZZI, 2015), ainda que se admita, em suas crenças, o fator transcendental e o sentido último da existência (FRANKL, 2007; 2008).

Considerando as congruências e incongruências nas discussões epistemológicas e ideológicas entre os respectivos temas, mas também, admitindo os diversos problemas que acometem a sociedade contemporânea, principalmente no que diz respeito as injustiças cometidas contra os idosos, vislumbramos a possibilidade do diálogo entre religião e política afastando-se, desta forma, dos calorosos debates que, em nossa concepção, constroem abismos

\footnotetext{
${ }^{3}$ Gohn (2011) estabelece uma diferença entre Espaço Público e Esfera Pública. Espaço público é um conceito mais abrangente, encontro de cidadãos plurais, refletindo a vida e espaço de interação. Esfera pública é um espaço de mediação e participação da sociedade.

REVISTA RELEGENS THRÉSKEIA - 2021 - UFPR
} 
e não pontes. Logo, o presente texto é um apelo aos direitos à cidadania do idoso, tendo como eixo epistemológico o conceito de espiritualidade e políticas públicas para a saúde. Tendo isso em mente, passemos a considerar os tópicos propostos.

\section{A fragilidade das políticas públicas do idoso}

Fernandéz e Camargo (2015, p. 14) afirmam que "[...] o envelhecimento é considerado um problema de saúde pública para todos os governos, pois a pirâmide populacional tem sido revertida e temos um aumento da população envelhecida, com as consequências sociais concomitantes que isso implica". Segundo estimativas, nos próximos cinquenta anos, a população idosa se multiplicará quatro vezes mais:

Em 2050, o número de pessoas com mais de 60 anos aumentará de 600 milhões para quase 2 bilhões, e prevê-se que a porcentagem de pessoas com 60 anos ou mais se duplique, passando de $10 \%$ para $21 \%$. Este aumento será maior e mais rápido nos países em desenvolvimento, onde se espera que a população idosa se multiplique por quatro nos próximos 50 anos (HERNANDÉZ; CAMARGO, 2015, p. 14).

Dois fatores têm contribuído para tal realidade: o "[...] aumento da expectativa de vida e a drástica redução da taxa de natalidade" (MANHÃES; ISTOE; SOUZA, 2015, p. 16). Assim sendo, surge a necessidade de políticas públicas que possam atender a essa demanda da população nas áreas da saúde, educação, assistência social e por melhores condições de vida.

O Estatuto do Idoso prevê, de fato, garantido por Lei Constitucional (Lei n. ${ }^{\circ} 10.741,1^{\circ}$ de outubro de 2003) melhorias nas condições de vida, assim como direito à saúde, à educação, à assistência social e a uma vida digna no envelhecimento. Essa lei, no dizer de Ferreira, Ferreira e Crespo (2015, p. 189), “[...] se consagra uma referência social”. Por esse viés, o direito, conforme postulado pelas autoras, tem a vertente sociológica "[...] que, por vezes atua diretamente como fator de educação, conservação e transformação" (p. 193) e, também, uma função conservadora. Nessa função, "[...] o direito previne conflitos, ordena e normatiza valores já existentes" (p. 193). De igual modo, o direito tem a função transformadora, “[...] ao dispor sobre novos assuntos, por demanda do próprio organismo vivo chamado sociedade, insere novos princípios e valores, quebrando paradigmas, modificando os costumes daquela sociedade e promovendo uma total reestruturação social" (FERREIRA; FERREIRA; CRESPO, 2015, p. 193).

Reitera-se que “[...] a Constituição determina de maneira clara que a família, a sociedade e o Estado têm o dever de amparar as pessoas idosas, assegurando sua participação na 
sociedade, defendendo sua dignidade e bem-estar, garantindo o direito à vida" (FERREIRA; FERREIRA; CRESPO, 2015, p. 193). Mas, na prática, de que forma as políticas públicas estão sendo implementadas visando aos direitos dos idosos no Brasil?

Em 1994, foi criada a Política Nacional do Idoso (PNI), pela Lei n. ${ }^{\circ}$ 8.842, sendo regulamentada pelo Decreto n. ${ }^{\circ}$ 1948/96, em que "[...] estabelece direitos sociais, integração, participação e autonomia dos idosos na sociedade" (FERREIRA; FERREIRA; CRESPO, 2015, p. 195). Adjunto ao PNI foi criado o Conselho Nacional do Idoso (CNDI), "[...] responsável por viabilizar o convívio e a integração do idoso na sociedade, até mesmo a sua participação na formulação de políticas públicas, projetos e planos voltados para sua faixa etária" (FERREIRA; FERREIRA; CRESPO, 2015, p. 195).

A culminância desses projetos ocorreu em 2003, quando foi aprovado o Projeto de Lei n. ${ }^{\circ} 3.561 / 1997$, "[...] que deu origem ao Estatuto do Idoso no Brasil" (FERREIRA; FERREIRA; CRESPO, 2015, p. 196). É interessante observar que nessa lei misturam-se as normas de caráter sancionador e pedagógico. Na visão de Ferreira, Ferreira e Crespo (2015), o Estatuto do Idoso tem tanto um caráter protetivo quanto também funciona como um "[...] mecanismo de educação e conscientização da sociedade" (p. 196).

É salutar, na visão das autoras, o destaque para o caráter da transformação social da lei. Mas, da outra ponta da pesquisa, o que se constata é um profundo abandono do idoso, tanto por parte das políticas públicas quanto da própria sociedade e família. Mendes et al. (2005) debatem a respeito da situação social do idoso no Brasil, tendo como eixo os aspectos demográficos, epidemiológicos e os aspectos psicossociais. Na perspectiva desses autores "[...] a qualidade de vida e o envelhecimento saudável requerem uma compreensão mais abrangente e adequada de um conjunto de fatores que compõem o dia a dia do idoso" (p. 423). Corroborando esse pensamento, Manhães, Istoe e Souza (2015) afirmam que o crescimento populacional do idoso tornou-se uma questão social. “Questão esta que pede grande atenção, pois está diretamente relacionada com crise de identidade; mudança de papéis; aposentadoria; perdas diversas e diminuição dos contatos sociais" (MENDES et al., 2015, p. 423).

Já na década de 1990, mediante pesquisas em cinco regiões do Município de São Paulo, constatou-se que 94\% dos idosos avaliados apresentavam mais de uma doença crônica e 32\% eram dependentes para suas atividades rotineiras e instrumentais de vida diária. Tal constatação retrata a preocupação com a situação social do idoso, demonstrando "[...] o envelhecimento sem qualidade e a carência no aspecto político e social que deem suporte para um envelhecimento saudável” (MENDES et al., 2015, p. 423). 
Ressalta-se que, embora haja um esforço das políticas públicas em atender as demandas dessa parcela da população, os problemas sociais que acometem o idoso são gigantescos. Esses problemas advêm, dentre outros fatores, de uma cultura capitalista em que o valor do ser humano está atrelado à produção. A própria política da aposentadoria, concebida como uma instituição social, é apontada por Mendes et al. (2015, p. 424) como geradora de crise:

A retirada da vida de competição, a auto-estima e a sensação de ser útil se reduzem. No início a maioria dos idosos se sente satisfeito, pois lhe parece ser muito bom poder descansar. Aos poucos, descobrem que sua vida tornou-se tristemente inútil. Nesta ausência de papéis é que podemos observar o verdadeiro problema do aposentado, sua angústia, sua marginalização e, muitas vezes o seu isolamento do mundo. Percebendo que ninguém necessita dele por estar isolado, recusado e excluído da sociedade, ele se sente cada vez mais angustiado, tornando difícil sua adequação ao mundo no qual vive. Aliado a esses fatores da aposentadoria, o idoso também enfrenta uma queda do nível de renda que, por sua vez, afeta a qualidade de vida bem como a saúde.

Essas discussões nos impõem uma questão séria: as políticas públicas, embora atuantes, são de dignidade social ou de afastamento? Referindo-se às leis de Política Nacional do Idoso, bem como da criação do CNDI, Mendes et al. (2015, p. 425) comentam:

Apesar da criação de novas leis de amparo a velhice, que evidenciam uma preocupação com esta crescente faixa etária, pouco tem sido feito para viabilizar o exercício dos direitos assegurados por estas leis. Ainda é muito parca a atuação governamental efetiva, voltada para este segmento da população. Sabe-se que até mesmo as iniciativas de caráter privado estão mais direcionadas para o assistencialismo, conduzindo a uma tendência de afastar os idosos de realizar atividades criadoras, favorecendo assim o seu isolamento da sociedade a qual pertence.

Nessa perspectiva de inserção social do idoso a sociedade, a família e as relações interpessoais possuem um caráter extraordinário de inclusão. Advoga-se, por esse viés, que a solução e as estratégias por um envelhecimento de qualidade devem ser elaboradas por todos os segmentos institucionais, de forma interdisciplinar e multidisciplinar (FERREIRA; FERREIRA; CRESPO, 2015; MANHÃES; ISTOE; SOUZA, 2015; MENDES et al., 2015). Nesse quesito, a família é primordial. Todavia, Caldas (2003) suscita a questão do envelhecimento com dependência, discutindo os atravessamentos que envolvem a responsabilidade e as demandas das famílias. Por se tratar de uma faixa etária vulnerável (o idoso dependente), o cuidador necessita de apoio das políticas públicas que viabilizem um tratamento humanizado aos idosos. Tal apoio envolve os aspectos emocionais e materiais:

[...] a família apresenta necessidades que vão desde os aspectos materiais até os emocionais, passando pela necessidade de informações. $\mathrm{O}$ aspecto material 
inclui recursos financeiros, questões de moradia, transporte e acesso a serviços de saúde. Por outro lado, essa família-cuidadora necessita de informação sobre como realizar os cuidados, incluindo a adaptação do ambiente ao idoso. Além disso, são importantes o suporte emocional, uma rede de cuidados que ligue a família aos serviços de apoio e meios que garantam qualidade de vida aos cuidadores principais (CALDAS, 2003, p. 777).

Camarano e Pasinato (2018) fazem uma análise sobre o envelhecimento populacional na agenda das políticas públicas, tanto em nível internacional quanto nacional. Se nos países desenvolvidos o fator socioeconômico permitiu uma maior eficácia no sistema de proteção social do idoso, nos países em desenvolvimento, inclusive no Brasil, a recessão e a crise fiscal travaram o processo de forma considerável. A agenda internacional para uma política pública de qualidade para o idoso tem o ponto de partida "[...] as duas assembleias das Nações Unidas, uma realizada em Viena, em 1982, e outra em Madri, em 2002" (p. 254).

Em Viena, foi aprovado um plano global de ação cujos objetivos "[...] eram garantir a segurança econômica e social dos indivíduos idosos bem como identificar as oportunidades para a sua integração ao processo de desenvolvimento dos países" (CAMARANO; PASINA, 2018, p. 254). O Plano Internacional de Ação estava ancorado sob sete áreas: "saúde e nutrição, proteção ao consumidor idoso, moradia e meio ambiente, família, bem-estar social, previdência social, trabalho e educação" (CAMARANO; PASINA, 2018, p. 255). A ressalva que se faz a este Plano Internacional de Ação eram os interesses políticos e econômicos e uma avaliação do idoso tendo como referência os países desenvolvidos. Ou seja, não era uma política de vulnerabilidade, mas, sim, de poder de compra:

A concepção do idoso traçada no plano era a de indivíduos independentes financeiramente e, portanto, com poder de compra. As recomendações eram dirigidas, em especial, aos idosos dos países desenvolvidos. Suas necessidades deveriam ser ouvidas, pois agregavam valor à economia e permitiam o desenvolvimento de um novo nicho de mercado. Por outro lado, o plano também foi fortemente dotado por uma visão da medicalização do processo de envelhecimento (CAMARANO; PASINA, 2018, p. 255).

Os desdobramentos das assembleias das Nações Unidas suscitaram dois olhares sobre o idoso e a sociedade. Numa perspectiva, associa-se o envelhecimento à dependência e a problemas sociais. Da outra ponta, os idosos podem contribuir significativamente para o desenvolvimento econômico e social. O resultado, no âmbito das Nações Unidas, a partir da Assembleia Geral de 1991, foi a adoção de dezoito princípios a favor da população idosa, sendo agrupados em cinco temas: independência, participação, cuidados, autorrealização e dignidade. 
Para cada eixo exige-se uma política pública diferenciada, conforme apontado por Camarano e Pasina (2018, p. 257):

A promoção da independência requer políticas públicas que garantam a autonomia física e financeira, ou seja, o acesso aos direitos básicos de todo ser humano: alimentação, habitação, saúde, trabalho e educação. Por participação, busca-se a manutenção da integração dos idosos na sociedade. Isso requer a criação de um ambiente propício para que possam compartilhar seus conhecimentos e habilidades com gerações mais jovens e de se socializarem. Os cuidados referem-se à necessidade do desfrute pelos idosos de todos os direitos humanos e liberdades fundamentais, através do cuidado familiar ou institucional. Auto-realização significa a possibilidade de os idosos fazerem uso de oportunidades para o desenvolvimento do seu potencial, por meio do acesso a recursos educacionais, culturais, espirituais e recreativos. Por último, o quesito dignidade requer que se assegure aos idosos a possibilidade de vida digna e segura, livre de toda e qualquer forma de exploração e maus-tratos.

Pode-se afirmar que, internacionalmente, a política pública para o idoso contempla tanto as suas vulnerabilidades quanto as possibilidades. São voltadas também para as questões familiares e a comunidade que assegurem um envelhecimento de qualidade e a promoção da solidariedade intergeracional, numa inter-relação entre Estado e a sociedade civil.

Para tanto, é necessário que as políticas públicas sejam concebidas com base na colaboração entre o Estado e a sociedade civil, de forma a construir um maior acesso ao entorno físico, aos serviços e recursos, aí incluída a atenção à proteção ambiental. Assim sendo, os idosos podem contribuir para o bemestar da sociedade e ao mesmo tempo se beneficiar dos direitos de se realizarem como cidadãos, de receberem atenção, serem independentes, participarem e serem tratados com dignidade [ONU (2001)] (CAMARANO; PASINA, 2018, p. 259).

No entanto, nos países desenvolvidos - e muito mais nos países em desenvolvimento tais políticas não alcançaram o êxito pelo qual foi proposto. Se nos primeiros a política de seguridade social é contraditória, em que a idade para a aposentadoria foi reduzida em 6,3 anos, nos países em desenvolvimento, como na África, a aposentadoria é um luxo.

Em alguns países subsaarianos e do Sul da África, estima-se que apenas de $5 \%$ a $10 \%$ da população trabalhadora estão cobertos pela seguridade social [ILO (2001)]. Além de a cobertura ser baixa, o valor do benefício também o é. Isso leva à continuação do idoso no mercado de trabalho, quase sempre na agricultura. Enquanto 40,5\% dos africanos com 64 anos e mais de idade trabalham, nos países desenvolvidos a proporção comparável estava em torno de 10\% [ILO (2001)] (CAMARANO; PASINA, 2018, p. 261-262).

Já o Brasil "É um dos pioneiros na América Latina na implementação de uma política de garantia de renda para a população trabalhadora que culminou com a universalização da seguridade social em 1988" (CAMARANO; PASINA, 2018, p. 262), remontando ao período 
colonial. Todavia, depreende-se das observações dessas autoras que "[...] as políticas do governo federal para a população idosa brasileira consistiam no provimento de renda para a população idosa que trabalhou de alguma forma e de assistência social para idosos necessitados e dependentes" (p. 265).

É dever da sociedade, da família e do Estado a proteção social do idoso. Assim preconiza a Constituição de 1988, no Título VIII, da Ordem Social, capítulo VII. A esse respeito, Camarano e Pasina (2018, p. 265) comentam:

O artigo 230, por exemplo, ressalta que o apoio aos idosos é de responsabilidade da família, da sociedade e do Estado, os quais devem assegurar a sua participação na comunidade, defender sua dignidade e bemestar e garantir o seu direito à vida. Em seu primeiro inciso, o artigo estabelece que os programas de cuidados dos idosos serão executados preferencialmente em seus lares. O segundo inciso amplia para todo o território nacional uma iniciativa que já vinha sendo observada em alguns municípios, desde o início da década de 1980: a gratuidade dos transportes coletivos urbanos para os maiores de 65 anos.

Ao contrário do artigo, tanto a sociedade quanto a família - e, também, a Constituição - deixam o idoso à margem. Ao longo da história do Brasil, as políticas públicas tentam, de todas as formas, viabilizar leis e projetos que promovam a qualidade de vida do idoso (CALDAS, 2003; MANHÃES; ISTOE; SOUZA, 2015; FERREIRA; FERREIRA; CRESPO, 2015; CAMARANO; PASINA, 2018). Mas, de igual modo, os autores apresentam os atravessamentos para uma política pública de qualidade para o idoso, apontando para uma política de exclusão e não de qualidade de vida. Assim sendo, existe uma disparidade entre o que a lei preconiza e o que de fato há na política pública do idoso.

O objetivo aqui proposto foi apontar tal disparidade, para, no próximo tópico, unir esforços na construção de uma proteção ao idoso pelo viés da espiritualidade, numa ação multidisciplinar. É o que se propõe debater no próximo tópico.

\section{Fé e Política: caráter teologal na transformação social}

O assunto é complexo, pois, como conciliar espiritualidade e políticas públicas na qualidade de vida do idoso? Talvez uma alternativa seja o debate em torno do conceito de Cidadania Deliberativa. Nesse conceito, a sociedade é um conjunto de atores que se institucionaliza e mantém parceria com o Estado para as políticas públicas diversas. Por esse viés, acontecem novas dimensões e novos modos de participação política para dirimir as desigualdades sociais (AVRITZER, 2012). Os direitos sociais, as leis contra o racismo, contra 
a violência, bem como a intervenção no campo da saúde perpassam pela nova configuração da sociedade, em que os atores não querem apenas existir, mas terem garantido o seu direito democrático de participação nas políticas públicas de intervenção.

Chassot e Allebrandt (2015), a partir do conceito de cidadania deliberativa habermasiano, defendem o diálogo e a interação na Gestão Social junto ao Conselho Municipal de Desenvolvimento Regional do Noroeste Colonial, no Estado do Rio Grande do Sul. Segundo Tenório (2008 apud CHASSOT; ALLEBRANDT, 2015, p. 2), na cidadania deliberativa, as decisões políticas devem perpassar pelo processo de debate, tendo como princípios a inclusão, o pluralismo, a igualdade participativa, a autonomia e o bem comum. Apesar dos atravessamentos, constatou-se na pesquisa que a participação coletiva (ação de vários atores da sociedade) contribui para o desenvolvimento e a qualidade de vida da população (CHASSOT; ALLEBRANDT, 2015, p. 19).

A sociedade contemporânea é marcada pela fragmentação, pela ausência de referências. "A modernidade líquida é uma civilização do excesso, da superfluidade, do refugo e de sua remoção" (BAUMAN, 2005, p. 124). Cultura do lixo, assim designada pelo Sociólogo Bauman (2005). Vive-se numa sociedade em que o valor humano está atrelado ao modo de produção. Nesse cenário político-social indaga-se: qual o valor do idoso? Soma-se, nessa teia de tensões entre política/sociedade e valoração humana, os próprios prejuízos físicos e mentais advindos com a idade.

Apropriando-se desse foco aponta-se para um grupo vulnerável socialmente que, grosso modo, é esquecido pela sociedade e pela política de Estado: o idoso. Quais são as políticas públicas para o idoso? De que forma a sociedade, de forma geral, tem se comportado perante o idoso? Não é intenção deste texto criticar os esforços dos órgãos governamentais e, muito menos, fazer o juízo de valor, mas abrir o diálogo para a inserção da espiritualidade como proposta existencial para o idoso. Diante disso, os grupos religiosos deixam de ser passivos em sua prática, atuando apenas nos ambientes eclesiológicos, e passam a ser agentes ativos (atores sociais), usando os seus rituais (JUNG, 1978) como instrumento de higienização da mente.

O problema central dessa abordagem é o lugar da religião ${ }^{4}$ na política. Lied e Hammes (2010) trazem algumas provocações que problematizam a relação entre religião e política. É possível que a primeira contribua de modo significativo com a transformação social. Mas como atuar no processo de decisão da sociedade num processo amplo que supere a política? Outras

\footnotetext{
${ }^{4}$ Por religião, nesta abordagem, entendem-se os grupos religiosos institucionalizados com os seus dogmas e doutrinas. 
questões são suscitadas: a religião tem por objetivo responder a relação da fé com a realidade social, econômica e política da sociedade ou a fé tem apenas um caráter subjetivo? A saída proposta por Lied e Hammes (2010, p. 1422) é evitar os extremos entre uma fé que se deixa manipular pelos interesses políticos e uma política que se desliga dos valores éticos e transcendentais:

É necessário desenvolver uma ideia menos ingênua e desvincular o uso da fé por políticos, mas também, não deixar cair no outro extremo em que a política se desliga do transcendente e dos valores éticos. Assim o agir político não é para o cristão de hoje algo que se pode evitar.

Diga-se de passagem, que a proposta da religião não é articular um manual de regras econômicas e sociais para o bem-estar comunitário. Esses são assuntos para outros campos da ciência. Todavia, sendo a religião um suspiro dos oprimidos (ALVES, 1984) é dela que advém - ou deveria vir - o apelo por justiça social. Logo, a relação religião e política se dá no campo dos direitos igualitários por dignidade humana sem perder, no entanto, as diferenças que os resguardam, como é o caso da relação Igreja e Estado:

Igreja e Estado têm diferentes finalidades, o espiritual e o temporal. Existe sempre o perigo de uma instituição sobrepor a outra ou de construírem paralelismos entre as duas instituições. Dessa forma, respeitando a distinção entre as duas ordens e a autonomia da ordem temporal, e por isso a diferença fundamental entre Igreja e Estado, afirma-se que ao mesmo tempo a existência de uma relação entre as duas ordens, na qual a Igreja atua no mundo não só como oferta de salvação às pessoas, mas também à história humana (LIED; HAMMES, 2010, p. 1424).

Júnior (2009), mesmo diante da problemática entre fé e política, busca elementos de mediação na relação entre elas. O seu eixo epistemológico é a partir e em vista da fé. Portanto, uma abordagem teológica. O ponto de partida, tal como Lied e Hammes (2010), é manter o caráter de autonomia das abordagens, sem perder de vista a influência da fé nas questões sociais:

Aqui, não faremos senão esboçar o modo como, na perspectiva da fé cristã, essa problemática deve ser compreendida e formulada, respeitando e potencializando tanto a unidade estrutural "fé - política" quanto a autonomia relativa da fé e da política, sem a qual tampouco se pode falar de sua unidade estrutural (JÚNIOR, 2009, p. 14).

Para que se estabeleça uma conexão entre fé e política é importante eliminar os seus elementos reducionistas e ideológicos. A partir da Encíclica Deus é amor, de Bento XVI, sobre a relação justiça e caridade, fé e política, Igreja e Estado, Júnior (2009) afirma que outro modo equivocado de analisar a questão é pensar fé e política de esferas e relatos autossuficiente e completos. Tomados dessa forma, mantém-se o caráter reducionista e ideologizante. "Fé e 
política não podem ser tomadas como 'esferas' ou 'relatos' completos e autossuficientes. A fé tem uma dimensão política constitutiva e a política tem um caráter teologal objetivo" (JÚNIOR, 2009, p. 15).

A proposta para um possível diálogo está no modelo estrutural, conforme apontando por Júnior (2009). Nessa abordagem, mantém-se o caráter de autonomia entre fé e política. Por outro lado, exige-se pluralidade qualitativa de elementos, funcionando na plataforma da unidade estrutural, "[...] para além de todo reducionismo/monismo e de todo dualismo" (p. 16). Desse modo,

[...] fé e política não se identificam sem mais (monismo), mas tampouco constituem "esferas" ou "relatos" autossuficientes que depois se poderá ou deverá "relacionar" (dualismo). São realidades (autonomia) respectivamente constituídas (unidade essencial) (JÚNIOR, 2009, p. 16).

Mas de que forma se constituiria a relação fé e política num sentido de intervenção social? Na vivência da fé e não em seus aspectos institucionais, sem, todavia, desconsiderá-las. Refere-se a uma dinâmica existencial entre fé e obra. Nesse sentido, é possível pensar a dimensão política da fé. "Numa palavra, ela consiste no seguimento de Jesus de Nazaré: viver como Jesus viveu. E esse modo ou jeito de viver diz respeito a todas as dimensões de nossa vida: pessoal, sexual, familiar, social, política, econômica, cultural, religiosa, gênero, etc" (JÚNIOR, 2009, p. 17). Nessa perspectiva, não há como dissociar o homem religioso da sociedade. "A política é constitutiva da fé, e não algo extrínseco, que casualmente se junta ou se relaciona com ela" (JÚNIOR, 2009, p. 19).

Pensar uma relação harmoniosa entre fé e política é utopia. Mas não as relacionar numa possibilidade de intervenção social é ignorância. Os termos amor e compaixão, embora sejam dispares em suas definições, são "[...] uma marca de todas as grandes religiões do mundo" (VAILLANT, 2010, p. 158). São termos que, se levados a efeito na vivência religiosa (CHAVES, 2017), podem contribuir para uma política pública humanizada e inclusiva. O pressuposto dessa afirmação se dá pelo fato de a religião trabalhar com as questões existenciais da vida e ter uma função social. É nessa perspectiva que Teixeira (2011) analisa a religião.

Mas como pensar a fé cristã, de base protestante, como possibilidade de intervenção social aliada às políticas públicas de saúde? Não é fácil abordar esse assunto, uma vez que se esbarra nas questões dogmáticas ${ }^{5}$ da Igreja e, por outro lado, no difícil diálogo entre fé e política. Os interesses escusos envolvendo líderes religiosos na política, bem como o uso da

\footnotetext{
${ }^{5}$ Entende-se por dogmas o conjunto de sistemas de crenças que fazem parte da doutrina de um seguimento eclesiástico.
} 
Bíblia para fins eleitoreiros e para fundamentar ideologias partidárias de grupos religiosos contribuem para essa conturbada relação. Para dirimir tais problemas talvez seja necessário um reposicionamento eclesiástico quanto aos seus $\operatorname{dogmas}^{6} \mathrm{e}$, na contrapartida, uma abertura, nas políticas públicas para os elementos constituintes da fé cristã, desvinculada do pacote institucional.

A Teologia Prática é uma sugestão para abrir o diálogo nessa questão. Rocha (2007) descortina um novo campo epistemológico para a atuação da Teologia na contemporaneidade. Para tanto, faz uma diferenciação entre Teologia Dogmático-Sistemática, aquela em que as Igrejas militam, para um novo modo de fazer Teologia, a que intervém nos problemas sociais. Apropriando-se das palavras de Libânio (2001), afirma que as principais ênfases da teologia dogmático-sistemática foram:

[...] "sistematizar, definir, expor e explicar as verdades reveladas", não só visando a "mostrar o que estava incluído no universo da fé, mas também a excluir as posições doutrinárias e oposição à fé, condenando os erros, resolvendo as dificuldades, refutando as falácias dos adversários". Ou, em outras palavras, afirmando a univocidade da verdade teológica (ROCHA, 2007, p. 64).

As perguntas do contexto contemporâneo são outras, demandando novas respostas. Assim sendo, a proposta para a modernidade é uma teologia dogmático-sistemática que busque desvelar sentidos e não definições (ROCHA, 2007). O teólogo Miranda (2011), ao mesmo tempo em que estabelece as diferenciações conceituais entre Teologia Histórica, Teologia Sistemática e Teologia Prática ${ }^{7}$, aponta para a implicação de cada uma em seu contexto de atuação. Nesse sentido, enquanto a missão do teólogo sistemático "[...] é elaborar um sistema teológico que expresse sua fé ou a fé de determinada corrente cristã”, o teólogo prático “[...] deve sempre mostrar a diferença que as suas conclusões fazem na vida cotidiana dos fiéis" (MIRANDA, 2011, p. 12). Concomitantemente, Zabatiero (2002, p. 7) apresenta a Teologia Prática como discurso crítico e construtivo da ação cristã no mundo presente:

Teologia Prática é discurso crítico e construtivo sobre a ação cristã no mundo presente. Fundamenta-se no discernimento da ação de Deus no mundo presente, e se constrói em diálogo - crítico e construtivo - com os discursos sobre a ação presente. A racionalidade da Teologia Prática é a de uma teoria crítico-discursiva da ação; e sua finalidade é contribuir para o aperfeiçoamento

\footnotetext{
${ }^{6} \mathrm{O}$ sentido aqui exposto é a apresentação dos conceitos epistemológicos da fé e a sua relação com o cotidiano das pessoas: suas potencialidades e limitações. Ou seja, a aplicação da fé nos problemas sociais, nas crises existenciais. Acredita-se que, para uma ação eficaz da fé nas políticas públicas, tal elemento deverá se dissociar do caráter confessional e doutrinário.

${ }^{7}$ Para mais esclarecimentos sobre o tema cf. MIRANDA, V. A. Fundamentos da teologia bíblica. São Paulo: Mundo Cristão, 2011.p. 11-17.
} 
da ação cristã no mundo, em resposta crística - na energia do Espirito Santo à ação presente de Deus no mundo.

É o discurso da ação cristã no mundo. É discurso crítico. É discurso construtivo. É discurso cujo paradigma da ação não se encontra na Igreja, mas em Jesus Cristo, em que o teólogo é a comunidade cristã. Por ser discurso crítico não é absolutizante. "A ação cristã deve ser acompanhada constantemente do discernimento do agir da comunidade cristã, na busca de acertar os nossos erros e os nossos acertos" (ZABATIERO, 2002, p. 9). Mas, igualmente, é discurso construtivo, pois não busca apenas apontar erros, mas responder de forma positiva a ação de Deus. Nesse sentido, a Teologia Prática

[...] visa construir comunidade de reconciliação, amor e justiça. As comunidades cristãs serão, assim, protótipos do Reino de Deus, serão primícias do Reino, espaços onde as pessoas poderão encontrar amizade, companheirismo, sentido para a vida e, especialmente, poderão encontrar Deus presente e atuante (ZABATIERO, 2002, p. 9).

Sendo assim, essa Teologia caminha em diálogo com o contexto ao qual está inserida. É um dar as mãos ao sofrimento, a dor e as lágrimas do ser humano. "Prática é o modo de ser da teologia" (ZABATIERO, 2005, p. 26). É a teologia em ação, exemplificado no paradigma do Bom Samaritano registrado no Evangelho de Lucas 10.25-37. "Fazer teologia, como nos recorda este episódio do Evangelho, não significa especular, mas encontrar novos estímulos para seguir a Jesus Cristo e dar testemunho das boas novas de seu reino" (ZABATIERO, 2005, p. 26).

Constata-se, mediante as observações aqui analisadas, a possibilidade para um entrelaçamento teórico entre fé e política, desde que respeitado aquilo que os une e diferencia. Evidenciou-se que tanto a política quanto a religião têm um caráter teologal, um sentido de salvação para a humanidade. Considerou, enquanto proposta dialógica entre fé cristã e política a Teologia Prática, um instrumento de ação cristã no mundo presente. Tal Teologia é deslocada do seu caráter professional e absolutizante e inserida no contexto social.

Delineando os pontos até aqui expostos temos, no primeiro momento, os problemas do idoso no Brasil e a deficiência das políticas públicas para com essa demanda da população. Em seguida, foi considerado um possível diálogo entre fé e política a partir da Teologia Prática. Mas ainda resta uma questão: como trabalhar a fé enquanto qualidade de vida do idoso e, dessa forma, atuar de forma interdisciplinar nas políticas públicas do idoso? É o que se pretende pensar no próximo tópico. 


\section{Espiritualidade judaico-cristã e políticas públicas do idoso: o cuidado do humano}

Segundo Silva (2008), tanto a fé quanto a política são fundamentais para o desenvolvimento humano. Embora a política pertença ao campo da secularização, também faz fronteira com a religião. Nesse sentido, o esforço dos militantes cristãos, no dizer de Silva (2008, p. 12), é articular as duas esferas e, também, “[...] politizar a religião e de religiosizar a política, introduzindo nesta, mediante o jogo de influências políticas, as cosmovisões e valores, os critérios e estilos da vida induzidos por aquela".

Medeiros (2014) afirma que a religião permeia os aspectos concretos da vida dos indivíduos envolvendo tanto as dimensões de princípios e valores quanto nas situações contingentes que surgem no quotidiano das pessoas. Por sua vez, Henning e Moré (2009), numa revisão de literatura de 127 artigos, analisando a interface temática entre Psicologia e Religião, afirmam que a espiritualidade se faz presente nos atendimentos clínicos de Psicologia, pois a sua influência não se restringe ao contexto sociocultural, mas também na constituição da subjetividade do indivíduo, expressa em crenças, valores, emoções e comportamentos a elas relacionados. Há uma inteligência existencial/espiritual no indivíduo que proporciona, dentre outras capacidades, a habilidade de utilizar recursos espirituais para resolver problemas na vida. Assim, a experiência religiosa contribui para o crescimento pessoal por meio da maior tolerância nos relacionamentos interpessoais, da inserção em grupos sociais, do autoconhecimento e desenvolvimento da empatia. Por isso, o universo religioso exerce uma função de inserção e/ou reinserção do indivíduo em um grupo, um meio sociocultural motivador e dotado de sentido.

Franklin (2008) traz, a partir de suas experiências no campo de concentração nazista, a importância e o valor do sentido último da existência - a fé em Deus - como elemento de sustentação dos soldados submetidos às crueldades do campo de batalha. Concomitante a essa visão, De Paula (2012) apresenta a relação da espiritualidade com a saúde, reiterando o valor do ritual e da liturgia, pautados numa fé em Deus, e não na confessionalidade religiosa, enquanto elemento contribuinte para a promoção da saúde. A alegria, o estudo e a oração são apresentados como Sistema Preventivo para a saúde ${ }^{8}$. O objetivo primário desse Sistema é adotar medidas socioeducativas para a saúde integral do indivíduo. Assim sendo,

\footnotetext{
${ }^{8}$ Segundo o teólogo De Paula (2012, p. 18), o Sistema Preventivo, embora sendo um conceito novo, veiculado pelos meios de comunicação, “[...] pode ser encontrado historicamente registrado, no âmbito da educação, nas instituições educativas religiosas que se espalhavam pela Europa, em especial na Itália do século XIX”.
} 
A religiosidade cristã é responsável por muitos estilos de vida e comportamentos adotados em nossa sociedade. Nós iremos trabalhar com aqueles que, de alguma forma, contribuem para a promoção humana através de suas práticas. Deixando de lado as diferenças confessionais, trataremos de considerar quatro elementos saudáveis para serem observados nos costumes de pessoas que buscam cultivar sua espiritualidade. São eles: alimentação, limpeza, sexualidade e descanso (DE PAULA, 2012, p. 19).

A prática da religião cristã é benéfica no controle dos geradores estressantes dessa sociedade, contribuindo para a promoção da saúde integral do indivíduo. "Participar de um grupo religioso gera consequências salutares para a vida do indivíduo. De maneira geral, podemos dizer que é um meio de apoio no âmbito social” (p. 20). O seu esboço de análise é “[...] a coesão social, a ideia de pertença, a continuidade das relações, bem como, o desenvolvimento da participação na comunhão e o companheirismo" (p. 20), que os grupos religiosos praticam elevando o sentimento "[...] de pertença a este determinado segmento de religiosidade, o que fortalece a autovalorização do indivíduo no meio social, bem como sua autoestima, por ser reconhecido e aceito em determinado grupo" (DE PAULA, 2012, p. 20). Por esse viés, o apoio social, a partir do vínculo com grupos religiosos, é salutar no enfrentamento da depressão em casos de luto.

Pelo exposto, a partir de Franklin (2008) e De Paula (2012) é possível considerar duas questões: o valor das crenças transcendentais e o das instituições religiosas cristãs no enfrentamento dos males que afetam a sociedade contemporânea, dentre eles os problemas da população idosa no Brasil. Mas que relação existe entre as crenças transcendentais, os grupos religiosos e o idoso? A relação está no sistema de crenças.

Um sistema de crenças pode ser definido a partir do reconhecimento de rituais religiosos públicos ou privados. Percebemos que, de alguma forma, contribuem para a saúde mental do ser humano por levá-lo a tomar uma atitude que possa ser a simples decisão de parar para orar (DE PAULA, 2012, p. 21).

Crer faz bem à saúde mental. Diante dos problemas contemporâneos, o que inclui o alto índice de doenças psíquicas, o abandono dos idosos, a ausência de políticas públicas que traga dignidade ao ser humano, não cabe mais um discurso discriminatório, sectário e materialista, estabelecendo a dicotomia entre Estado e Sociedade Civil. É necessário e urgente rever os posicionamentos das instituições religiosas no cenário brasileiro, mas discriminá-las, jamais. A oração, os rituais, os grupos religiosos, as confissões e a liturgia produzem efeitos benéficos na psique humana. No caso da oração, “[...] são partes do dia a dia das pessoas e são formas de interação terapêutica” (DE PAULA, 2012, p. 21). 
A saúde não é uma questão tão somente biológica, tendo como eixo de intervenção ciências cartesianas como a Psicologia e a Psiquiatria. A Psicanálise representa tal ciência na Psicologia. Apropriando-se desse argumento, Franklin (2007) desloca tal Psicologia do campo reducionista da Psicanálise. Essa Psicologia reduziu “[...] os fenômenos humanos à facticidade psicofísica, descuidou-se da pessoa 'propriamente dita' em sua totalidade, que é o objeto da logoterapia” (p. 6). Nessa perspectiva, inaugura-se uma Psicologia espiritual. Exclui-se, nessa abordagem, qualquer comprometimento com a confissão religiosa. Todavia, não se descartam os efeitos profiláticos ou psicoterapêuticos da transcendência. "Entretanto, poderão resultar efeitos profiláticos ou psicoterapêuticos quando a pessoa experimenta alívio psicológico ao considerar sua transcendência, ao encontrar o sentido último da vida em Deus ou ao sentir-se ancorada no absoluto" (FRANKLN, 2007, p. 7).

Em sua análise, há um sentido último da existência (FRANKIN, 2008). Diante da realidade sub-humana dos soldados, a mercê de todo tipo de crueldade, Franklin inaugurou a Logoterapia, uma psicoterapia centrada no sentido. Nessa abordagem, não se descarta o sentido último da existência, denominado de suprassentido. Os elementos religiosos são considerados como fonte terapêutica, o que inclui a transcendência. "No entanto, quando o paciente está sobre o chão firme da fé religiosa, não se pode objetar ao uso do efeito terapêutico das suas convicções espirituais" (FRANKLIN, 2008, p. 142).

Da mesma forma, o psicólogo e teólogo Amatuzzi (2015) relaciona a religião ao sentido da vida e a estrutura enquanto orientação e devoção. Apropriando-se do pensamento de Erick Fromm (1974), apresenta a raiz psicológica da religião ligada à insatisfação do ser humano, necessitando, assim, de um encontro harmonioso com a própria existência:

O ser humano, por sua condição existencial, é um insatisfeito. 'Mesmo que a fome, a sede e os desejos sexuais do homem estejam completamente satisfeitos, ele não está satisfeito [...]. É nesse desequilíbrio que se radica a necessidade do reencontro de uma harmonia, vivida como perdida, e expressada como tal nos mitos do paraíso ou das origens em várias culturas (AMATUZZI, 2015, p. 21).

Existem elementos que diferenciam a natureza humana do animal. Dentre eles estão as formas de responder à necessidade de sentido. $\mathrm{O}$ homem tem a necessidade de harmonia $\mathrm{e}$ sentido para a vida. Assim sendo, os mais variados sistemas filosóficos e religiosos apresentam respostas de sentido para o ser humano, incluindo os sistemas religiosos monoteístas. É importante ressaltar que o sentido da vida não está, necessariamente, atrelado ao conceito de transcendência, mas que tal conceito faz parte da busca do sentido do homem ao longo da 
história. Não há como descartar tal realidade. Nos sistemas religiosos monoteístas, “[...] nosso mundo não é caótico e absurdo, mas corresponde aos designíos de um Deus que nos ama e protege, e em quem podemos confiar" (AMATUZZI, 2015, p. 23).

Mas o que é religião para o idoso e como ela se manifesta enquanto superação dos conflitos, tornando-a útil nessa fase do desenvolvimento humano? Amatuzzi (2015), ao avaliar o sentimento religioso em cada fase do desenvolvimento, destaca a religiosidade do idoso como: a libertação dos apegos e o encontro com uma forma de vitalidade mais espiritual; viver momento a momento da vida, com os seus percalços, porém, “[...] vislumbrando na penumbra um sentido maior, na esperança de quem se sabe agora depende de um poder maior” (p. 217). No lado mais desenvolvido há uma relativização das instituições e os aspectos externos. É uma religião de vida. Pelo lado menos desenvolvido, evidencia-se uma religião presa aos esquemas, às regras, como uma proteção contra o medo. "O ser religioso e o viver são quase a mesma coisa; estar religado é o que sustenta e dá sentido ao viver" (AMATUZZI, 2015, p. 217). Nesse caso, as instituições, mesmo sendo importantes, não são a base da experiência religiosa.

Fica evidente, nos depoimentos apresentados por Amatuzzi (2015), uma relação com o mistério. Seja a divindade, seja a vida. Amatuzzi (2015), tal como Franklin (2007; 2008), apresenta a religião relacionada ao sentido da existência e, de forma específica, a religião na eminência da morte.

O idoso, como vivencia perdas e as compensa com novos apegos, parece estar chamado a vivenciar a vida para além dos apoios materiais que já começam a faltar. A vivência religiosa aqui, vivida nessa plenitude, dá um senso de libertação e de olhar compreensivo e tolerante para as diversas situações da vida. Mas o oposto é possível também: uma religião intolerante, presa aos aspectos externos, rígida, focada nos apegos, digamos assim. Parece claro que a primeira alternativa é mais saudável psicologicamente. A proximidade da morte é uma situação especial no que diz respeito à elaboração de significados religiosos: a pessoa colocada de forma aguda diante da realidade última e dos significados derradeiros. O desafio aqui é aceitar a autodestruição e entregarse em paz; a não concretização disso corresponde a um morrer atormentado. Essa paz tem embutida nela a referência a um polo de interlocução transcendente à própria vida (AMATUZZI, 2015, p. 223).

É certo que a espiritualidade pode ser pensada por várias dimensões, e não necessariamente na perspectiva da espiritualidade cristã. O teólogo Sathler-Rosa (2014) deixa isso em evidência ao analisar os sentidos de espiritual e espiritualidade no contexto de cuidar. Espiritualidade - em termos teológicos, espírito ou espiritual - relaciona-se à natureza do ser humano criado. É um ser espiritual, denominado por Butzke (2008 apud SATHLER-ROSA, 2014, p. 129) de homo spiritualis. Nesse sentido, a existência do ser humano não se dá apenas 
no plano material e transitório. Antes, "[...] é um ser qualificado como espiritual. Como tal, é um ser vocacionado a coexistir em relacionamentos: consigo, com o próximo, com a Criação e com o Criador" (SCHNEIDER, 2008 apud SATHLER-ROSA, 2014, p. 129). Por outro lado, a espiritualidade também pode ser usada como um termo técnico, remontando ao uso francês spiritualité. No século XVII foi usado por ordens religiosas católicas

[...] para descrever a comunhão com Deus e o exercício da fé. Espiritualidade é, então, definida como a manifestação existencial da constituição ontológica do ser humano: é um ser espiritual. A espiritualidade abrange a fé, os ritos e rituais próprios e a vivência cotidiana. Inclui, também, os vários âmbitos da existência: individual, familiar, comunitário, social, política, ecológico e outros (BUTZKE, 2008 apud SATHLE-ROSA, 2014, p. 129).

É uma espiritualidade do cuidado do ser. Uma proposta integral da saúde. A espiritualidade judaico-cristã é vista por Sathle-Rosa (2014) como transformação das condições existenciais. Cura e paz, na literatura bíblico-teológica, são termos intercambiáveis, denotando a saúde integral do ser humano. Ademais disso, as comunidades funcionavam como pastorais, não deixando o ser humano a mercê de suas mazelas. "Ser 'pastoral' implicava cuidado mútuo, zelar, acompanhar, ser solidário" (SATHLER-ROSA, 2014, p. 131). No cristianismo primitivo a função das comunidades era zelar pelo ser humano, relegando aos oficiais, posteriormente, tal função. Parece não haver espaço para o abandono e para as desigualdades. Essa era a espiritualidade judaico cristã.

A intenção desses modos de cuidar é zelar, na perspectiva da espiritualidade judaico cristã, pela realização nos sujeitos, em sua trajetória existencial, de sua marca essencial: perceber-se como "seres espirituais", isto é, "seres viventes". Cabe-lhes, igualmente, conceber o mundo e o outro como talhados para conferir sentido à existência, conforme vocação original implícita na Criação (SATHLER-ROSA, 2014, p. 132).

É nesse contexto que a espiritualidade entra no debate de políticas públicas do idoso. São perceptíveis os problemas da população idosa no Brasil. Abandono - do poder público, da sociedade e da família -, ausência de suporte social, políticas públicas fragilizadas, sem falar nos problemas subjetivos, próprios dessa faixa etária (MANHÃES; ISTOE; SOUZA, 2015; FERREIRA; FERREIRA; CRESPO, 2015; MENDES et al., 2015). As crenças e o suporte social são elementos que conferem sentido à vida (FRANKLIN, 2007; 2008; DE PAULA, 2012; AMATUZI, 2015). Nesse contexto, política e fé devem ter um caráter teologal, tendo como função o aspecto social (ZABATIERO, 2002; 2005; ROCHA, 2007; JÚNIOR, 2009; LIED; HAMMES, 2010; TEIXEIRA, 2011). Sendo assim, a espiritualidade resgata o sentimento de valoração do indivíduo; humaniza o coração das pessoas e, consequentemente, 
retira o idoso de sua condição de não valia e abandono. Afinal de contas, cuidar, em sua raiz etimológica, é sinônimo de curar (SATHLER-ROSA, 2014, p. 133).

\section{Considerações finais}

Reitera-se nesta pesquisa o conflito entre teoria e prática no que diz respeito às Leis de amparo ao idoso. Em se tratando de políticas públicas do idoso, há uma discrepância, embora haja esforços para dirimir os problemas, entre o que preconiza a lei e o que de fato existe enquanto intervenção na qualidade de vida do idoso. As pesquisas apontaram para uma política de exclusão tanto do poder público quanto da sociedade e da família. Logo, o modo de intervenção não está circunscrito aos órgãos governamentais, mas a sociedade como um todo. Advoga-se, por esse viés, o debate entre espiritualidade e políticas públicas.

Considerando tal situação, buscou-se aliar o elemento fé e política, argumentando que tanto um quanto o outro tem um caráter teologal, no sentido de oferecer salvação para os dilemas existenciais e sociais. No entanto, sugeriu-se que, em se tratando de uma fé de base cristã, é necessário que ela se distancie dos seus aspectos dogmáticos para uma ação prática em seu contexto comunitário. É possível, por meio da Teologia Prática, uma ação relevante das instituições religiosas relacionada à intervenção social, o que inclui o idoso. Conquanto haja complexidades envolvendo as instituições religiosas, apelou-se para o diálogo a favor do ser humano.

Nessa direção apontamos a espiritualidade enquanto base ontológica do ser, permeando todos os elementos concretos da existência humana. Crer faz bem à saúde. Cuidar também é curar. Sendo assim, a espiritualidade confere sentido ao ser, promovendo o desenvolvimento humano, mesmo na eminência da morte. Em seu aspecto positivo e experiencial, a prática da religião para o idoso é mais vivencial do que institucionalizada e livre dos apegos e do medo. Da mesma forma, eleva o ser humano à condição de transcendência.

Sendo assim, dada as circunstâncias de injustiça social, as dificuldades dos órgãos governamentais em atenuar os problemas e a ânsia de dirimir os calorosos debates em torno da política e religião que nos propomos a pensar o tema. Propositalmente nos distanciamos dos valores ideológicos, seja político ou religioso. As redes midiáticas dão conta destes elementos. A nossa reflexão é prática. Optamos em apontar o lado prático das abordagens e as suas potencialidades na intervenção social. 
Sendo assim, para que servem as discussões, por exemplo entre direita e esquerda, conservadorismo e liberalismo, senão para perpetuar um lugar de exclusão? Estaria as redes midiáticas, o campo acadêmico, político e religioso prestando um serviço ou desserviço a comunidade ao defender um posicionamento ideológico que dissocia as instâncias políticas e religiosas? Quem estará apto para exercer a função espiritual no contexto de políticas públicas sem se contaminar com a confessionalidade? São temas complexos e até certo ponto utópicos na tentativa de promover reconciliações. Por isso justificamos o nosso desvio epistemológico. Desta feita, nos contentamos em pontuar as relevâncias, ainda que entre limites e possibilidades, deixando em aberto a ampla discussão em torno do assunto.

\section{REFERÊNCIAS}

ALVES, R. O suspiro dos oprimidos. São Paulo: Paulinas, 1984.

AMATUZI, M. M. Psicologia do desenvolvimento: a religiosidade nas fases da vida. São Paulo: Ideia \& Letras, 2015.

AVRITZER, L. Sociedade civil e Estado no Brasil: da autonomia à interdependência política. Opin. Pública, v. 18, n. 2, nov. 2012.

BAUMAN, Z. Vidas desperdiçadas. Tradução de Carlos Alberto Medeiros. Rio de Janeiro: Jorge Zahar Ed., 2005.

BIRMAN, P. (Org.). Religião e Espaço Público. São Paulo: Attar Editorial, 2003.

CALDAS, C. P. Envelhecimento com dependência: responsabilidades e demandas da família. Cad. Saúde Pública, Rio de Janeiro, v. 19, n. 3, p. 773-781, maio/jun. 2003.

CAMARANO, A. A.; PASINATO, M. T. O envelhecimento populacional na agenda das políticas públicas. Disponível em: <http://ipea.gov.br/agencia/images/stories/PDFs/livros/Arq_16_Cap_08.pdf>. Acesso em: 27 mar. 2018.

CHASSOT, J. P. C.; ALLEBRANDT, S. L. Gestão social e critérios de cidadania deliberativa presentes em espaços públicos: o caso dos conselhos municipais de desenvolvimento do noroeste colonial gaúcho. In: Seminário Internacional sobre Desenvolvimento Regional. Globalização em Tempos de Regionalização - Repercussões no Território, 7., 2015, Santa Cruz do Sul, RS, Anais... Santa Cruz do Sul, RS, Brasil, 9 a 11 de setembro de 2015.

CHAVES, F. da S. Saúde e espiritualidade. São Paulo: Fonte Editorial, 2017.

DE PAULA, D. Espiritualidade: uma questão de saúde? Protestantismo em Revista, São Leopoldo, RS, v. 27, p. 17-24, jan./abr. 2012. 
FERNANDÉZ, A. H.; CAMARGO, C. de B. Prefácio. In: MANHÃES, F. C.; ISTOE, R. S. C.; SOUZA, C. H. M. de. Envelhecimento em foco: abordagens interdisciplinares I. Rio de Janeiro: Brasil Multicultural, 2015.

FERREIRA, L. C. P.; FERREIRA, B. C. G. V.; CRESPO, C. P. Estatuto do idoso: um agente de mudança social. In: MANHÃES, F. C.; ISTOE, R. S. C.; SOUZA, C. H. M. de. Envelhecimento em foco: abordagens interdisciplinares I. Rio de Janeiro: Brasil Multicultural, 2015.

FRANKL, V. E. A presença ignorada de Deus. Tradução Walter O. Schulupp e Helga H. Reinhold. 10 ed. São Leopoldo: Sinodal; Petrópolis: Vozes, 2007.

. Em busca de um sentido: um psicólogo no campo de concentração. Traduzido por Walter O. Schlupp e Carlos C. Aveline. 25 ed. São Leopoldo: Sinodal; Petrópolis: Vozes, 2008.

GOHN, M. da G. Movimentos sociais na contemporaneidade. Revista Brasileira de Educação, v. 16, n. 47, maio/ago. 2011.

HENNING, M. C.; MORÉ, C. L. O. O. Religião e psicologia: análise das interfaces temáticas. Revista de Estudos da Religião, p. 84-114, dez. 2009.

JUNG, C. G. Psicologia e religião. Tradução do Pe. Dom Mateus Ramalho Rocha. Petrópolis: Vozes, 1978.

JÚNIOR, F. de A. Fé - Política: uma abordagem teológica. Horizonte, Belo Horizonte, v. 7, n. 15, p.13-31, dez. 2009.

LIED, L. L.; HAMMES, E. J. Fé e política: o desafio da igreja para propor um mundo de paz. In: Mostra de Pesquisa da Pós-Graduação - PUCRS, 5., 2010. Anais... Rio Grande do Sul, RS, 2010.

MANHÃES, F. C.; ISTOE, R. S. C.; SOUZA, C. H. M. de. Envelhecimento em foco: abordagens interdisciplinares I. Rio de Janeiro: Brasil Multicultural, 2015.

MEDEIROS, O. H. R. de. Religião e problema moral: Segmentação social e crescente individuação. In: Congresso Português de Sociologia Sociedades Contemporâneas: Reflexividade e Acção Atelier: Quotidiano, Crenças e Religiosidades, 5., 2014. Actas dos ateliers... $2014 . \quad$ Disponível em: <http://www.aps.pt/cms/docs_prv/docs/DPR4628ef1b1872c_1.pdf>. Acesso em: 25 jul. 2014.

MENDES, M. R. S. S. B.; GUSMÃO, J. L. de; FARO, A. C. M.; LEITE, R. de C. B. de O. A situação social do idoso no Brasil: uma breve consideração. Acta Paul Enferm., v. 18, n. 4, p. 422-426, 2005.

MIRANDA, V. A. Fundamentos da teologia bíblica. São Paulo: Mundo Cristão, 2011.

ROCHA, A. R. Teologia sistemática no horizonte pós-moderno: um novo lugar para a linguagem teológica. São Paulo: Editora Vida, 2007. 
SATHLER-ROSA, R. Cuidado espiritual como fator de integralidade (saúde) do Ser: funções históricas do cuidado na tradição judaico-cristã. Rev. Pistis Prax., Teol. Pastor., Curitiba, v. 6, n. 1, p. 127-144, jan./abr. 2014.

SILVA, L. G. de F. A representação social da relação fé e política na escola Pe. Humberto Plummen. Dissertação (Mestrado em Ciências da Religião) - Programa de Mestrado em Ciências da Religião, Universidade Católica de Pernambuco, Recife, PE, 2008.

TEIXEIRA, F. (Org.). Sociologia da religião: enfoques teóricos. Petrópolis, RJ: Vozes, 2011. . Peter Berger e a religião. In: TEIXEIRA, F. (Org.). Sociologia da religião: enfoques teóricos. Petrópolis, RJ: Vozes, 2011.

VAILLANT, G. V. Fé: evidências científicas. Tradução Isabel Alves. Barueri, SP: Manole, 2010.

XAVIER, M. O conceito de religiosidade em C. G. Jung. PSICO, Santa Catarina, v. 37, n. 2, p. 183-189, maio/ago. 2006.

ZABAtiero, J. P. T. A Teologia Prática e seu lugar na Igreja. Revista Teologia Prática FATE-BH, Belo Horizonte, v. 1, n. 1, p. 7-15, 2002.

ZABATIERO, J. Fundamentos da teologia prática. São Paulo: Mundo Cristão, 2005. 